\title{
Leitura e argumentação: potencialidades do uso de textos de divulgação científica em aulas de Física do ensino médio
}

\section{Reading and arguing: potential use of popular science texts in middle of Physical education in high school}

Daniele Correia $^{1}$. Emanoela Decian ${ }^{2}$. Inés Prieto Schmidt Sauerwein ${ }^{2}$

\begin{abstract}
Resumo: Neste artigo são apresentados os resultados obtidos a partir de uma sequência de atividades didáticas que envolveram o uso de estratégias de leitura e Textos de Divulgação Científica em aulas de Física da $2^{\mathrm{a}}$ série do Ensino Médio. A sequência de atividades com Textos de Divulgação Científica teve $\mathrm{o}$ intuito de investigar os indícios de evolução dos alunos com relação à leitura e à argumentação. Constatou-se que o uso sistemático e recorrente dos Textos de Divulgação Científica nas aulas propiciou o desenvolvimento das habilidades relacionadas às expressões oral e escrita dos alunos. Ainda, percebeu-se que as tarefas propostas nas etapas de pré/durante/pós-leitura, para trabalhar os distintos textos, mostraram-se fundamentais para: promover a articulação entre o texto e o conteúdo de Física; envolver os alunos durante os processos de leitura e discussão do texto; avaliar o que os alunos sabiam antes e o que aprenderam depois de perpassar por cada etapa de leitura.
\end{abstract}

Palavras-chave: Ensino de física. Ensino médio. Divulgação científica. Leitura. Argumentação.

\begin{abstract}
This paper presents results from a sequence of educational activities that involve the use of reading strategies and popular science texts in physics classes of the 2nd year of High School. The activities sequence with popular science texts aiming to investigate the effect on the students' progress regarding to reading and argumentation. It was found that the systematic and repeated use of popular science texts in classes led to the development of skills related to oral and written expression of the students. It was also noticed that the proposed tasks of pre/during/post-reading stages were fundamental to promote the relationship between the text and the physics content. These tasks help to engage students during the process of reading and text discussion, as well as to evaluate what the students knew before and what they learned after the reading step.
\end{abstract}

Keywords: Physics teaching. High school. Popular science texts. Reading. Argumentation.

\footnotetext{
${ }^{1}$ Universidade Federal de Mato Grosso do Sul (UFMS), Instituto de Química, Campo Grande, MS, Brasil. E-mail: $<$ d.correia@ufms.br>.

${ }^{2}$ Universidade Federal de Santa Maria (UFSM), Santa Maria, RS, Brasil.
} 


\section{Introdução}

O ensino de Física, de forma geral, vem sofrendo atualizações, tanto na forma de abordar os conteúdos científicos, quanto na incorporação de assuntos que fazem parte da vida cotidiana dos alunos. Pesquisas na área de Educação em Ciências têm apontado que os Textos de Divulgação Científica (TDC) têm potencial de vincular os conteúdos disciplinares ao cotidiano do aluno (ROCHA, 2012) e que seu uso em sala de aula pode contribuir na formação do sujeito-leitor, capaz de, ao sair da escola, continuar a obter e analisar criteriosamente informações de natureza científico-tecnológica (ALMEIDA; RICON, 1993).

Nesse sentido, a utilização de TDC em aulas de Física pode propiciar discussões entre professor e alunos que envolvam não só a vinculação entre o conteúdo científico ensinado e seus aspectos sociais, políticos, ambientais, históricos e tecnológicos, mas também promover o desenvolvimento de habilidades relacionadas às expressões oral e escrita necessárias à formação do cidadão crítico capaz de se posicionar e argumentar sobre o que lê. Aspectos esses necessários à formação do bom leitor e que, no entanto, nem sempre são trabalhados nas aulas de Física.

Nesse contexto, é necessário salientar que é papel também do professor de Física estimular o hábito da leitura e escrita nas aulas (SILVA, 1998), de forma a contribuir para o desenvolvimento gradativo da capacidade de interpretação, compreensão e argumentação dos textos lidos, além de colaborar para o gosto pela leitura. A leitura de materiais de divulgação científica auxilia a ilustrar a aplicabilidade dos conteúdos científicos trabalhados em sala de aula e propicia o desenvolvimento dos conteúdos procedimentais e atitudinais que possivelmente permanecerão após a formação escolar.

Diante do exposto, este artigo apresenta a análise de uma sequência de Atividades Didáticas (AD) que envolveram o uso de TDC extraídos das revistas de divulgação científica Ciência Hoje e Scientific American Brasil, do jornal O Estado de São Paulo e do site de notícias Globo (G1). As AD foram implementadas nas aulas de Física em uma turma da 2. ${ }^{a}$ série do Ensino Médio de uma escola pública da cidade de Santa Maria, Rio Grande do Sul, Brasil. Assim, o estudo teve o intuito de investigar quais foram os indícios de evolução dos alunos em relação à interpretação e à argumentação.

\section{Leituras de TDC e argumentação nas aulas de Física}

É crescente o número de publicações de pesquisas da área de Ensino de Ciências envolvendo a relação entre leitura, escrita e ensino de Física. Os TDC têm sido sugeridos nessas pesquisas como capazes de complementar o livro didático (ABREU; MASSI; QUEIROZ, 2007; MAFFIA et al., 2002; ZANOTELLO; ALMEIDA, 2013). Outras pesquisas destacam que a leitura de materiais de divulgação possibilita ao aluno o acesso a uma maior diversidade de informações, o desenvolvimento de habilidades de leitura, apropriação de conceitos, formas de argumentação e conhecimento de elementos de terminologia científica (FERREIRA; QUEIROZ, 2012; MARTINS; CASSAB; ROCHA, 2001).

Alguns autores como Almeida e Ricon (1993), Ribeiro e Kawamura (2005) apontam que, apesar de existirem dificuldades na utilização dos TDC em sala de aula, como a falta de aprofundamento de detalhes específicos sobre determinado assunto, ainda assim esses materiais 
se caracterizam como uma poderosa ferramenta didática, pois os TDC apresentam linguagem acessível para abordar temas atuais sobre ciência, tecnologia (SALÉM; KAWAMURA, 1996; SILVA; KAWAMURA, 2001; ZAMBONI, 2001) e não exagerarem no uso de simbologia matemática como, em geral, acontece nos livros didáticos (FERREIRA; QUEIROZ, 2012; TERRAZZAN; GABANA, 2003).

O professor pode utilizar o TDC em sala de aula em diferentes momentos e com finalidades distintas, desde que o assunto abordado no TDC esteja em consonância com o conteúdo ensinado e/ou a ser ensinado. É importante que toda atividade que envolva a leitura de textos pelos alunos venha a ser complementada com atividades estratégicas de pré-leitura, durante a leitura e pós-leitura, tais como as propostas por Solé (1998) e Moss e Loh (2012). De acordo com Solé (1998), as atividades de pré-leitura têm o intuito de motivar a leitura, ou seja, elas devem permitir que o aluno faça previsões e levante hipóteses sobre as informações do texto, bem como estabeleça conexões entre seus conhecimentos prévios e o assunto abordado no texto. As atividades realizadas durante a leitura devem favorecer a retomada das previsões iniciais e a verificação do que foi compreendido a partir da leitura do texto. Já as atividades de pós-leitura devem permitir que o aluno reavalie seus conhecimentos iniciais, estabeleça diferenciação entre o que sabia antes e o que passou a compreender após a leitura do texto, faça vinculação entre as informações do texto e o conteúdo estudado, além de sintetizar as principais ideias/informações do texto. Com isso, sugere-se que a leitura de TDC seja articulada ao uso dessas atividades estratégicas (pré/durante/pós-leitura) para garantir o envolvimento dos alunos durante todo o processo de leitura e discussão do texto.

Com relação à argumentação, Eemeren, Grootendorst e Kruiger (1987) apontam que ela é uma atividade social de natureza discursiva, na qual indivíduos expressam pontos de vista diferentes sobre um tema defendendo seus posicionamentos com vista a convencer seus interlocutores. Já para Leitão e Almeida (2000), a argumentação é uma atividade que envolve uma multiplicidade de perspectivas e pressupõe oposição entre as opiniões dos envolvidos. Assim, entende-se que, no contexto da sala de aula, a argumentação é uma forma de interação comunicativa em que docentes e alunos confrontam seus saberes e opiniões sobre um tema com o propósito de convencer um ao outro, a partir de critérios científicos.

A análise da argumentação dos estudantes é feita sob diferentes enfoques por pesquisadores da área de Ensino de Ciências. São encontrados estudos em que ela é feita utilizando o modelo de Toulmin (1958) (SÁ; QUEIROZ, 2007), ou ainda por meio da análise das interações discursivas em sala de aula (ASSIS; TEIXEIRA, 2007).

Para obter um panorama dos artigos sobre o uso de TDC em aulas de Física do Ensino Médio (espaços formais de ensino), fez-se um levantamento nos principais periódicos nacionais ${ }^{3}$

\footnotetext{
${ }^{3}$ Revistas analisadas até o primeiro número publicado em 2015: Ciência \& Educação (2003-2015), Revista Brasileira de Ensino de Física (1979-2015), Revista Brasileira de Educação (2000-2015), Revista Brasileira de Pesquisa em Educação em Ciências (2001-2015), Cadernos CEDES (1997-2015), Educação em Revista (20062015), Ensaio: Pesquisa em Educação em Ciências (2004-2015), Investigações em Ensino de Ciências (online) (1996-2015), Alexandria (UFSC) (2008-2015), Caderno Brasileiro de Ensino de Física (1994-2015), Cadernos de Educação (UFPel) (2004-2015), Ciência \& Ensino (1996-2015), Educação \& Sociedade (1997-2015), Experiências em Ensino de Ciências (2006-2011).
} 
da área de ensino avaliados com conceito A1, A2 e B1 pelo programa Qualis da Capes ${ }^{4}$ Para a identificação desses artigos, optou-se por selecionar aqueles que apresentavam em seus títulos as seguintes palavras: "leitura", "Física”, "texto", "estratégias de leitura", "popularização da ciência” e "divulgação científica". Foi a partir dessas palavras que os trabalhos foram selecionados prioritariamente. Em alguns casos, tais palavras não apareciam no título do trabalho, mas constavam em seus resumos, que foram consultados quando havia dúvida em relação à sua seleção.

A partir dessa busca, encontrou-se um total de 11 artigos, em que os autores relatavam o desenvolvimento de atividades de ensino com TDC em aulas de Física. Os manuscritos foram organizados de acordo com as atividades propostas pelos autores nas etapas de pré/durante/ pós-leitura, conforme descrito a seguir:

- Pré-leitura: como exemplos de atividades são relatadas a proposição de questões (ALMEIDA; SILVA; MACHADO, 2001; DIAS; SANTOS; SOUZA, 2004; SILVA; KAWAMURA, 2001) ou problemas (BORGES; RODRIGUES, 2005);

- Durante a leitura: concomitantemente à leitura do texto, os autores mencionam que foi solicitado que os alunos respondessem a um questionário (ALMEIDA; MOZENA, 2000; ALMEIDA; SILVA; MACHADO, 2001; BORGES; RODRIGUES, 2005; SILVA; ALMEIDA, 2015), elaborassem uma síntese das ideias principais do texto (SILVA; ALMEIDA, 2014), respondessem a um questionário e destacassem as dúvidas sobre o texto (ALMEIDA; SILVA; BABICHAK, 1999), elaborassem um seminário (SILVA; KAWAMURA, 2001) ou ainda produzissem um texto relacionando o conteúdo com o texto lido (SETLIK; HIGA, 2014);

- Pós-leitura: como exemplos de atividades são relatadas a apresentação de um seminário (SILVA; KAWAMURA, 2001), a proposição de questionário (ASSIS; TEIXEIRA, 2007; DIAS; SANTOS; SOUZA, 2004; SILVA; ALMEIDA, 2014, 2015) ou a discussão do texto (ALMEIDA; SILVA; BABICHAK, 1999; ASSIS et al., 2012).

Ao analisar esses artigos, constatou-se que eles se referem a atividades pontuais envolvendo o uso do TDC e possuem objetivos diversos. Entretanto, não apresentam explicitamente a preocupação em desenvolver, por meio dessas atividades com TDC, as habilidades de leitura e escrita por meio de estratégias de pré/durante/pós-leitura e, tampouco, a de estimular a capacidade de argumentação dos alunos. Também se observou que nenhum dos artigos analisados contemplaram as etapas de pré/durante/pós-leitura em uma mesma atividade. Essa sequência de etapas é importante no trabalho com TDC, pois é a partir de cada atividade proposta em cada uma dessas etapas que o professor poderá avaliar a evolução na aprendizagem, ou seja, o que o aluno sabia antes e o que aprendeu depois de passar por todas as etapas de leitura. Além disso, as tarefas propostas durante essas etapas motivam os alunos a se envolverem no processo de leitura. É importante destacar que as habilidades relacionadas às expressões oral e escrita só serão desenvolvidas com a inserção de práticas frequentes e periódicas de leitura.

A revisão nos periódicos nacionais mostra que há carência de pesquisas que tenham o intuito de acompanhar a evolução dos alunos com relação à compreensão de leitura, à escrita e à capacidade de argumentação mediante o uso sistemático e periódico de TDC nas aulas de

\footnotetext{
${ }^{4}$ Disponível em: <https://sucupira.capes.gov.br/sucupira/public/consultas/coleta/veiculoPublicacaoQualis/ listaConsultaGeralPeriodicos.jsf>. Acesso em: 25 out. 2017. 
Física. Assim, este artigo apresenta os resultados da implementação de uma sequência de AD utilizando TDC, cujo objetivo foi propor aos alunos atividades que promovessem o desenvolvimento das habilidades de leitura, compreensão e argumentação, utilizando, para tanto, diferentes estratégias de leitura e escrita, focando na articulação do conhecimento científico e sua relação com o cotidiano, com a ciência e a tecnologia.

\section{Encaminhamentos metodológicos}

Este trabalho foi desenvolvido durante a pré-regência e regência do estágio supervisionado em Física na Universidade Federal de Santa Maria (UFSM). No período de pré-regência ${ }^{5}$, uma das autoras deste artigo planejou um conjunto de aulas envolvendo uso de TDC que foram executadas no período de regência de estágio (segundo semestre de 2014). Assim, o presente trabalho investigou a evolução da aprendizagem dos alunos do Ensino Médio com relação à interpretação e à argumentação a partir da execução de uma sequência de AD que envolveu o uso de TDC. As AD foram implementadas nas aulas de Física em uma turma da $2^{a}$ série do Ensino Médio de uma Escola Pública e envolveram cerca de 20 alunos. A sequência de AD englobou o uso de distintos TDC associados às estratégias de leitura, sendo que cada uma delas contemplou a realização de atividades de pré/durante/pós-leitura (SOLÉ, 1998). Os textos trabalhados foram: (1) Tudo o que você sabe sobre calorias está errado (DUNN, 2013); (2) Potência? Torque? Consumo? Saiba o que considerar ao comprar carro (MARUM, 2014); (3) Gasolina ou etanol: qual vale mais a pena? (MOTTA, 2013); (4) Para ouvir melhor (MANFRIN; MACEDO, 2014). O Quadro 1 ilustra a relação dos textos trabalhados e as estratégias de leitura utilizadas em cada um deles.

Conforme se verifica no Quadro 1, foram propostas diferentes atividades de leitura e escrita para as etapas de pré/durante/pós-leitura, com o intuito de promover o desenvolvimento das habilidades de leitura, escrita e argumentação por meio de diferentes formas de interação texto-leitor na realização das tarefas propostas. As AD com TDC foram implementadas no decorrer do segundo semestre de 2014, conforme ilustrado no Quadro 2.

\footnotetext{
${ }^{5}$ No período de pré-regência, uma das professoras responsáveis pela disciplina de Estágio Supervisionado em Ensino de Física ofereceu às estagiárias uma oficina de leitura e escrita que subsidiou o planejamento das aulas com TDC. Após o término da oficina, realizou-se o planejamento das aulas com TDC pelas estagiárias. Concluída essa etapa, deu-se a apresentação das atividades didáticas com TDC por meio de aulas simuladas e, posteriormente, ocorreu a execução em sala de aula de cada atividade didática com TDC no período de regência.
} 
Quadro 1. Síntese das atividades desenvolvidas com TDC

\begin{tabular}{|c|c|c|c|c|}
\hline \multirow{2}{*}{ 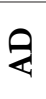 } & \multirow{2}{*}{ Objetivos da AD } & \multicolumn{3}{|c|}{ Descrição das estratégias } \\
\hline & & Pré-leitura & Durante a leitura & Pós-leitura \\
\hline 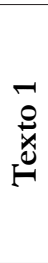 & $\begin{array}{l}\text { - Abordar a unidade Caloria; } \\
\text { - Promover a leitura, escrita e } \\
\text { argumentação; } \\
\text { - Estabelecer relações entre o texto } \\
\text { e o conteúdo. }\end{array}$ & $\begin{array}{l}\text { Questões } \\
\text { iniciais }\end{array}$ & $\begin{array}{l}\text { - Síntese da(s) ideia(s) } \\
\text { principal(is) do texto; } \\
\text { - Identificação de novas } \\
\text { informações trazidas do } \\
\text { TDC. }\end{array}$ & $\begin{array}{l}\text { - Discussão do } \\
\text { texto e das tarefas } \\
\text { de pré/durante a } \\
\text { leitura; } \\
\text { - Produção de } \\
\text { resumo. }\end{array}$ \\
\hline & $\begin{array}{l}\text { - Abordar potência dos motores; } \\
\text { - Promover a leitura, escrita e } \\
\text { argumentação; } \\
\text { - Estabelecer relações entre o texto } \\
\text { e o conteúdo. }\end{array}$ & $\begin{array}{l}\text { Situações- } \\
\text { problema }\end{array}$ & $\begin{array}{l}\text { - Identificação de } \\
\text { trechos do texto } \\
\text { concordantes ou } \\
\text { discordantes com a } \\
\text { solução apresentada para } \\
\text { a situação problema da } \\
\text { etapa de pré-leitura; } \\
\text { - Elaboração de } \\
\text { questões. }\end{array}$ & $\begin{array}{l}\text { - Discussão do } \\
\text { texto e das tarefas } \\
\text { de pré/durante a } \\
\text { leitura; } \\
\text { - Produção de } \\
\text { resumo. }\end{array}$ \\
\hline 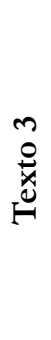 & $\begin{array}{l}\text { - Discutir o Ciclo de Carnot; } \\
\text { - Segunda Lei da Termodinâmica } \\
\text { e o rendimento das máquinas } \\
\text { térmicas; } \\
\text { - Promover a leitura, escrita e } \\
\text { argumentação; } \\
\text { - Estabelecer relações entre o texto } \\
\text { e o conteúdo. }\end{array}$ & $\begin{array}{l}\text { Questões } \\
\text { iniciais }\end{array}$ & $\begin{array}{l}\text { - Síntese da(s) ideia(s) } \\
\text { principal(is) do texto; } \\
\text { - Elaboração de } \\
\text { questões. }\end{array}$ & $\begin{array}{l}\text { - Discussão do } \\
\text { texto e das tarefas } \\
\text { de pré/durante a } \\
\text { leitura; } \\
\text { - Proposição de } \\
\text { problema. }\end{array}$ \\
\hline 守 & $\begin{array}{l}\text { - Abordar as qualidades fisiológicas } \\
\text { do som; } \\
\text { - Promover a leitura, escrita e } \\
\text { argumentação; } \\
\text { - Estabelecer relações entre o texto } \\
\text { e o conteúdo. }\end{array}$ & $\begin{array}{l}\text { Questões } \\
\text { iniciais }\end{array}$ & $\begin{array}{l}\text { - Síntese da(s) ideia(s) } \\
\text { principal(is) do texto; } \\
\text { - Elaboração de } \\
\text { questões. }\end{array}$ & $\begin{array}{l}\text { - Discussão do } \\
\text { texto e das tarefas } \\
\text { de pré/durante a } \\
\text { leitura; } \\
\text { - Produção de } \\
\text { uma propaganda. }\end{array}$ \\
\hline
\end{tabular}

Fonte: elaborado pelos autores.

Para investigar os indícios de avanços dos estudantes com relação à leitura, à interpretação e à argumentação, na medida em que foram trabalhados os TDC ao longo de um semestre letivo, foram utilizados como fonte de dados os registros escritos dos alunos para as tarefas de pré-leitura, durante a leitura e pós-leitura, assim como as anotações da professora (em formação), gravações das aulas em áudio e os diários da prática pedagógica (elaborados após o término de cada $\mathrm{AD}$ ). A análise dos registros escritos dos estudantes (referentes às atividades desenvolvidas para cada TDC trabalhado, ver Quadro 1) está baseada no procedimento de análise de conteúdo proposta por Bardin (2004). Essa metodologia é estruturada em três polos cronológicos: (a) Pré-análise; (b) Exploração do material; e (c) Tratamento dos resultados, inferência e interpretação. Para a autora, a pré-análise é um período de organização: "Corresponde 
a um período de intuições, mas tem por objetivo tornar operacionais e sistematizar as ideais iniciais, de maneira a conduzir a um esquema mais preciso do desenvolvimento das operações sucessivas, num plano de análise" (BARDIN, 2004, p. 89). Nessa fase, instituem-se diretrizes que devem ser flexíveis para que possam ser alteradas no decorrer do trabalho. Em um primeiro momento, estabelece-se um contato com os documentos de análise, "deixando-se invadir por impressões e orientações". A partir desse primeiro contato se define o corpus, que é o conjunto de documentos que serão submetidos aos procedimentos analíticos. A exploração do material é a fase de sistematizar as decisões estabelecidas na pré-análise. Posto de outra forma, colocar em prática o que foi planejado. A fase de tratamento corresponde ao momento em que os resultados obtidos são tornados significativos e válidos. A partir da análise das respostas chegou-se a duas categorias: Interpretação e Argumentação.

Quadro 2. Cronograma das AD com TDC

\begin{tabular}{|c|c|c|c|c|}
\hline \multirow{2}{*}{ AD } & $\begin{array}{c}\text { Total de aulas } \\
\text { disponibilizadas }\end{array}$ & Pré-leitura & $\begin{array}{c}\text { Durante a } \\
\text { leitura }\end{array}$ & Pós-leitura \\
\cline { 3 - 5 } Texto 1 & 3 horas-aula $(135 \mathrm{~min})$ & $\begin{array}{c}\text { Realizada no dia } \\
18 / 9 / 14(1 \text { hora-aula })\end{array}$ & $\begin{array}{c}\text { Tarefa para } \\
\text { casa }\end{array}$ & $\begin{array}{c}\text { Realizada em 22/9/14 } \\
(2 \text { horas-aula })\end{array}$ \\
\hline Texto 2 & 2 horas-aula $(90 \mathrm{~min})$ & \multicolumn{2}{|c|}{ Realizadas em $31 / 10 / 14$} \\
\hline Texto 3 & 2 horas-aula $(90 \mathrm{~min})$ & \multicolumn{2}{|c|}{ Realizadas em $14 / 11 / 14$} \\
\hline Texto 4 & 2 horas-aula $(90 \mathrm{~min})$ & \multicolumn{2}{|c|}{ Realizadas em $28 / 11 / 14$} \\
\hline
\end{tabular}

Fonte: elaborado pelos autores.

\section{Análise e Discussão dos Resultados}

A primeira categoria, Interpretação, está centrada na análise das sínteses da(s) ideia(s) principal(is) dos TDC (ver Quadro 1). Investigou-se se os alunos sintetizaram, com suas próprias palavras, a(s) ideia(s) principal(is) de cada texto. De acordo com Solé (1998), a síntese da ideia principal é o resultado do diálogo interativo entre as ideias do autor e do leitor.

Assim, na tarefa proposta para ser realizada durante a leitura do Texto 1, percebeu-se que grande parte dos alunos $(83 \%)$ teve dificuldade em sintetizar de forma clara e coerente a(s) ideia(s) principal(is) do TDC. Esse fato pode ser justificado pelo pouco hábito de leitura e escrita dos estudantes. Também, constatou-se que as sínteses elaboradas pelos alunos apresentavam ideias extraídas na íntegra do TDC (cerca de 25\%) ou informações específicas do texto (aproximadamente 33\%). Essa segunda situação pode ser evidenciada nos seguintes excertos:

Aluno 19: $O$ autor explica que as pessoas devem se alimentar de forma mais saudável ingerindo alimentos integrais, em vez de alimentos altamente processados.

Aluno 24: $O$ autor explica o que é calorias, o quanto ela varia de um alimento para outro. 
Ao analisar esses extratos, percebe-se que os alunos 19 e 24 iniciam seus resumos utilizando o termo $o$ autor. Isso é uma evidência de que eles fizeram uma leitura de sentido único, aquela assumida de antemão e, supostamente, autorizada pelo autor do texto. Esse tipo de leitura é a que, nas palavras de Kleiman (2007), reflete uma concepção autoritária, ou seja, a percepção (equivocada) de que há apenas uma única maneira de ler e de interpretar o texto.

O desejável seria que os alunos tivessem interpretado o TDC com suas próprias palavras, algo que nesse caso não ocorreu. Dito de outra forma, o fato de os alunos terem feito uma leitura de sentido único e, em sua grande maioria, terem se limitado a transcrever apenas algumas ideias abordadas pelo autor do TDC, acabou por comprometer a autoria das sínteses, na perspectiva de interpretação alternativa, defendida por Solé (1998).

Com relação à tarefa proposta para ser realizada durante a leitura do Texto 3 e do Texto 4, observou-se que $76 \%$ e $84 \%$ dos alunos, respectivamente, demostraram autoria na confecção de suas sínteses da(s) ideia(s) principal(is). Alguns exemplos estão ilustrados a seguir:

\begin{abstract}
Aluno 24 [Texto 3]: A ideia é discutir sobre qual combustivel é mais vantajoso na hora de abastecer (álcool ou gasolina?). Mas é preciso levar em conta alguns aspectos como: lugar onde você abastece, qual polui menos e qual oferece maior desempenho. Também tem um cálculo simples que auxilia na hora de decidir qual combustivel é mais econômico em determinada situação. Temos então um exemplo de aplicação do conteúdo de motores e rendimento, algo que não conbecia.
\end{abstract}

\begin{abstract}
Aluno 19 [Texto 4]: mostrar aos jovens como os fones de ouvido podem ser prejudiciais tanto no volume alto quanto no baixo, porque depende de quanto tempo você usa o fone de ouvido. Também discute sobre os diferentes tipos de fone e como escolber o ideal. Aprendi algumas coisas novas sobre o fone in-ear que uso, vi que tem um tempo ideal para se usar o fone depois pode prejudicar o ouvido. No men caso, percebi que estou usando demais o fone.
\end{abstract}

Como pode ser visto nesses excertos, os alunos produziram suas sínteses na perspectiva de interpretação defendida por Solé (1998). Fica evidente que as produções textuais dos alunos ilustram uma interpretação alternativa à da apresentada nos TDC, isto é, os alunos parecem ter percebido que a leitura prevê interação entre autor-texto-leitor, salienta-se que essa postura não foi verificada nas duas primeiras AD com TDC.

Outro aspecto importante como se destacou anteriormente, é que os alunos, ao longo das sucessivas implementações, passaram a utilizar as estratégias de leitura trabalhadas em sala de aula para fazer a leitura individual dos TDC, sendo que os estudantes utilizavam suas anotações pessoais para sustentar seus argumentos durante as discussões em aula. Essa mudança no modo de ler o TDC parece ser um sinal de que os estudantes perceberam o real significado e/ou função das leituras de TDC nas aulas de Física. Em outras palavras, parece que os alunos compreenderam que as leituras de TDC possibilitam novos aprendizados até então desconhecidos por eles. Isso ficou evidente nas falas dos estudantes 19 e 24.

Também se evidenciaram melhorias significativas tanto na qualidade das informações quanto na extensão das sínteses dos alunos. Isso fica explícito quando comparamos as produções textuais dos alunos 19 (AD com os Textos 1 e 4) e 24 (AD com os Textos 1 e 3). 
Acredita-se que os indícios de evolução percebidos na leitura, na interpretação e na escrita dos alunos possam estar vinculados à sequência de textos trabalhados nas aulas de Física, que propiciou, ao longo do semestre, o desenvolvimento de habilidades de leitura e escrita por meio das tarefas solicitadas nas etapas de pré/durante/pós-leitura.

A segunda categoria, Argumentação, foi baseada na análise das tarefas de pré-leitura e pós-leitura dos TDC e das observações registradas nos diários da prática pedagógica. A argumentação foi intensamente trabalhada ao longo das atividades com TDC, tanto por meio das tarefas solicitadas nas etapas de pré/durante/pós-leitura, quanto nas discussões de cada TDC (etapa de pós-leitura) em sala de aula. Ambas tinham o intuito de instigar o aluno a refletir, a opinar e a argumentar sobre o assunto lido nos TDC.

A categoria Argumentação foi dividida em três subcategorias ${ }^{6}:$ Argumentação baseada no senso comum, Argumentação baseada nos conteúdos físicos e Argumentação baseada em informações do TDC.

Argumentação baseada no senso comum: abrange as respostas elaboradas pelos alunos que apresentaram explicações baseadas em impressões cotidianas sobre o assunto, mesmo que por vezes equivocadas do ponto de vista científico.

Ao analisar as tarefas de pré-leitura desenvolvidas com o Texto 1, evidenciou-se que os alunos restringiram suas respostas às observações cotidianas sobre assunto. Em uma das tarefas de pré-leitura do Texto 1, inquiriu-se os estudantes se a quantidade de calorias absorvidas por uma pessoa após ingerir determinado alimento era exatamente aquela descrita no rótulo. A seguir, são ilustrados os exemplos de respostas dadas a esse questionamento: Aluno 15: "Sim, se comermos as mesmas quantidades indicadas". Aluno 17: "Sim, se for o mesmo produto e a mesma quantidade."

Percebe-se que as respostas dos alunos 15 e 17 são baseadas em conhecimentos cotidianos, ou seja, eles não apresentaram argumentos científicos para responder à questão. Após a leitura do texto, os alunos foram novamente inquiridos sobre a relação entre a quantidade de calorias absorvidas e aquelas informadas nos rótulos dos alimentos. Constatou-se que a grande maioria dos alunos reformulou as respostas iniciais e passou a apresentar explicações baseadas em suas leituras do TDC, podendo ser verificado nas respostas dos alunos 15 e 17.

\footnotetext{
Aluno 15: Não, porque em alguns casos (amendoins, fibras, alimentos crus, etc.) se gasta muito mais energia para os alimentos serem digeridos.
}

Aluno 17: Não, porque o valor dos rótulos é estimado (o cálculo não leva em consideração a complexidade da digestão) e não concreto.

Algo similar aconteceu na tarefa de pré-leitura do Texto 2, em que cerca de $73 \%$ dos alunos responderam corretamente à situação-problema, embora tenham apresentado justificativas baseadas no senso comum (ver excerto do aluno 20). Os outros $27 \%$ apresentaram em suas respostas ideias equivocadas, também baseadas no senso comum (ver excerto do aluno 34).

${ }^{6}$ Adaptadas de Assis e Teixeira (2007). 
Isso pode ser visto nas respostas que seguem, dadas pelos alunos à seguinte situação -problema: "Um carro, com motor 1.0 sobe uma ladeira com 5 pessoas dentro e suas respectivas bagagens. Outro carro, com motor 1.4, sobe a mesma ladeira, também com 5 pessoas dentro e suas bagagens. Em qual desses carros o consumo de combustível será maior? Por quê?" Aluno 20: "O carro 1.0 em comparação ao 1.4 gasta muito menos." Aluno 34: "No 1.4, por ser maior demanda mais combustivel que o 1.0."

$\mathrm{Na}$ tarefa de pós-leitura, o número de alunos que acertou a questão aumentou (82\%) e mesmo aqueles que já haviam acertado a questão na etapa de pré-leitura, modificaram suas respostas, sendo que estas passaram a apresentar argumentos trazidos ao longo do texto. Isso pode ser observado nos seguintes exemplos:

Aluno 20: Um carro 1.0 tem um motor com menor potência que o 1.4, assim transforma o combustivel em capacidade para subir, fazendo com que gaste mais combustivel.

Aluno 34: O 1.0, por que o motorista está forçando o motor para subir a ladeira, o que demanda maior consumo de combustivel.

Percebe-se que a resposta do aluno 20 dada à situação-problema, antes de ler o TDC, está baseada em expressões cotidianas "o carro 1.0 gasta mais". Entretanto, após a leitura do TDC, o mesmo aluno apresentou argumentos de caráter científico. Sendo assim, sua explicação passou a envolver assuntos que foram abordados no TDC e em aula, como a potência dos motores e os combustíveis. Já o aluno 34 apresentou uma resposta equivocada antes da leitura do TDC; porém, após a leitura, modificou sua resposta e, assim como o estudante 20, também apresentou de forma sucinta argumentos baseados nas discussões feitas a partir do TDC.

Salienta-se que as atividades com TDC foram inseridas regularmente ao longo do semestre letivo, portanto, os avanços com relação aos modos de leitura e argumentação foram se tornando mais explícitos principalmente a partir do Texto 3. É importante salientar que nas AD com os TDC 1 e 2 , a postura frente ao TDC assumida pelos estudantes era a leitura - busca de informações ${ }^{7}$ (GERALDI, 1984; SOUZA, 2000). Em contrapartida, durante o processo de implementação das AD com os Textos 3 e 4, percebeu-se que os estudantes modificaram seus modos de leitura dos TDC, isto é, eles passaram a interagir com os textos durante todo o processo de leitura e discussão dos textos (utilização de estratégias de leitura trabalhadas em aula). Somando-se a isso, percebeu-se que os alunos começaram, especialmente a partir das duas últimas AD com TDC, a se posicionarem criticamente sobre as informações lidas, fato que foi evidenciado nas discussões em sala e nas atividades de pós-leitura.

Essa mudança na postura de leitura dos estudantes sugere que eles perceberam que o ato de ler é um processo de interação entre autor-texto-leitor, no qual interferem, entre outros

\footnotetext{
${ }^{7}$ Quando o objetivo do leitor é a busca de informações. Assim, o que define a interlocução que se estabelece nesse processo de leitura é justamente seu objetivo - a extração de informações do texto para uma determinada demanda. Este tipo de leitura está associado ao "para que ler este ou aquele texto", buscar esta ou aquela informação (GERALDI, 1984; SOUZA, 2000).
} 
aspectos, as experiências de vida, os valores, as crenças, as relações intertextuais ${ }^{8}$, o conhecimento prévio do leitor, o nível de proximidade deste leitor com o texto, além dos objetivos que orientam o ato de ler, sem deixar de considerar os aspectos análogos referentes ao autor (RÖSING, 2003). Com isso, a postura perante o TDC observada nas AD com os Textos 3 e 4 foi a leitura do texto-pretexto ${ }^{9}$ (GERALDI, 1984; SOUZA, 2000).

Aliás, os próprios alunos relataram, em diferentes ocasiões (formais e informais), que não estavam habituados a interagir com os textos lidos e, tão pouco, haviam participado de práticas de leitura nessa composição (organização em etapas de pré/durante/ pós-leitura). Segundo eles, a leitura em sala de aula ocorria nas aulas de Português e História, sendo que ela se limitava à leitura individual de pequenos textos dos livros didáticos, seguida pela resolução de questões, as quais eram facilmente respondidas a partir da cópia literal de trechos dos textos lidos. Essa prática se configura no que denominam Nascimento e Souza (2003) de modelo tradicional de leitura que, segundo as autoras, é a modalidade mais exercitada nas escolas.

Portanto, os avanços com relação às expressões oral e escrita dos estudantes, percebidos ao longo das implementações das atividades com TDC, dão indícios de que as leituras de TDC associadas às estratégias de leitura potencializaram a contextualização e a abordagem dos conteúdos físicos, bem como a evolução dos alunos com relação à leitura, à escrita e à capacidade de argumentação. Nessa direção, acredita-se que as mudanças observadas nos modos de leitura dos estudantes podem ser atribuídas, aparentemente, a uma possível ressignificação do ato de ler (RÖSING, 2003). Essas mudanças na postura de leitura dos alunos também podem estar associadas aos modos de leitura exercitados pela professora em formação durante as discussões em aula, em que ela buscava, a partir de trechos específicos (previamente selecionados) de cada TDC, estabelecer e aprofundar as relações entre as informações do TDC e o conteúdo de Física ensinado e, ao mesmo tempo, incentivar os estudantes a argumentar criticamente sobre as informações trazidas nos TDC e/ou debatidas em sala de aula.

Argumentação baseada nos conteúdos físicos: abrange as respostas elaboradas pelos alunos que apresentaram explicações baseadas nos conteúdos de Física e/ou que estabeleceram conexões entre os conteúdos de Física e as informações do texto.

Ao analisar as respostas dos alunos dadas à tarefa de pré-leitura proposta na $\mathrm{AD}$ com o Texto 4, pode-se verificar que eles tentaram respondê-la utilizando argumentos relacionados ao conteúdo de ondas sonoras vistos em aulas anteriores. Cabe salientar que, no caso específico do Texto 4, o conteúdo (características fisiológicas do som) já havia sido

\footnotetext{
${ }^{8}$ Expressão que deriva do termo intertextualidade, "designa ao mesmo tempo uma propriedade constitutiva de qualquer texto e o conjunto das relações explícitas ou implícitas que um texto ou um grupo de textos determinado mantém com outros textos" (CHARAUDEAU; MAINGUENEAU, 2006, p. 288, grifos omitidos). Isto é, um intertexto é a relação com outros textos que pode ou não acontecer quando no momento de leitura de um texto específico.

${ }^{9}$ Nesse tipo de leitura é o pretexto, ou seja, a atividade a ser realizada a partir da leitura, que definirá o tipo de interlocução que se estabelece entre o leitor e o texto. A leitura texto-pretexto pode propiciar a intertextualidade, isto é, quando os leitores se remetem a outros textos para aprofundar seus conhecimentos e/ou argumentar sobre determinado assunto.
} 
trabalhado anteriormente, o que não aconteceu nas aulas com os TDC anteriores. Nas três primeiras atividades com TDC, os conteúdos físicos foram trabalhados concomitantemente com as atividades propostas em cada etapa de leitura, sendo que a devida vinculação entre as informações de cada TDC e os conteúdos físicos foi priorizada durante as discussões dos textos em sala de aula.

Dessa forma, no último TDC trabalhado (Texto 4), ao responderem à questão proposta na etapa de pré-leitura, "Como os sons chegam aos nossos ouvidos?", 88\% dos alunos apresentaram argumentos baseados no conteúdo de ondas sonoras (visto em aulas anteriores), conforme os seguintes exemplos. Aluno 20: "Através das ondas sonoras que se propagam no ar." Aluno 34: "Por meio das ondas sonoras, que precisam de um meio para se propagar, o ar."

Nesse momento, parece que a relação entre as informações do TDC e o conteúdo físico (no caso ondas sonoras) ocorreu de maneira espontânea por parte dos alunos, provavelmente, de um lado, pelo fato de o texto ter sido trabalhado em aula posterior à abordagem do conteúdo de acústica. De outro, pelo TDC apresentar uma linguagem acessível para abordar o assunto "fones de ouvido", que faz parte do cotidiano dos alunos. Nessa direção, o resultado relatado está em consonância com o trabalho de Rocha (2012), no qual o autor aponta que o TDC tem o potencial de estabelecer e vincular os conteúdos disciplinares ao cotidiano do aluno.

Desse modo, pode-se perceber que o TDC é um bom recurso para ser utilizado nas aulas que tenham como propósito articular leitura e a abordagem de conteúdos científicos e ir além, isto é, fomentar o desenvolvimento das habilidades relacionadas às expressões oral e escrita (FERREIRA; QUEIROZ, 2012; MARTINS; CASSAB; ROCHA, 2001).

Argumentação baseada em informações do TDC: abrange as respostas elaboradas pelos alunos que apresentaram explicações baseadas em informações do TDC, atribuindo credibilidade ou fidelidade às respostas.

Ao analisar os registros escritos (respostas das tarefas) e orais (gravações em áudio) de cada AD com TDC, evidenciou-se que muitos alunos apresentavam em suas respostas informações extraídas do texto. Isso pode ser notado com mais clareza na atividade de pós-leitura do último TDC, em que cada grupo de alunos produziu uma propaganda referente a um dos quatro fones de ouvido abordados no texto. Os exemplos estão ilustrados na Figura 1.

A propaganda ilustrada na Figura 1, lado esquerdo, foi baseada nas informações contidas no TDC. Este grupo teve o cuidado de criar um cartaz criativo que chamasse a atenção do consumidor. Além disso, o grupo buscou ressaltar as características sobre a estrutura e o modelo do fone, alertando que esse modelo é menos prejudicial ao aparelho auditivo que os demais modelos descritos no TDC. No caso da propaganda ilustrada na Figura 1, no lado direito, também foram utilizadas informações do TDC; entretanto, esse grupo não focou em divulgar o produto pela imagem, ou seja, a propaganda ficou restrita às características do fone. Ambas as propagandas foram de autoria dos alunos, justificando a presença de aspectos que os alunos julgaram mais importantes e/ou que deveriam constar em uma propaganda. 
Figura 1. Propaganda referente ao fone headphone do grupo 4 (lado esquerdo). Propaganda referente ao fone Earbud do grupo 2 (lado direito)

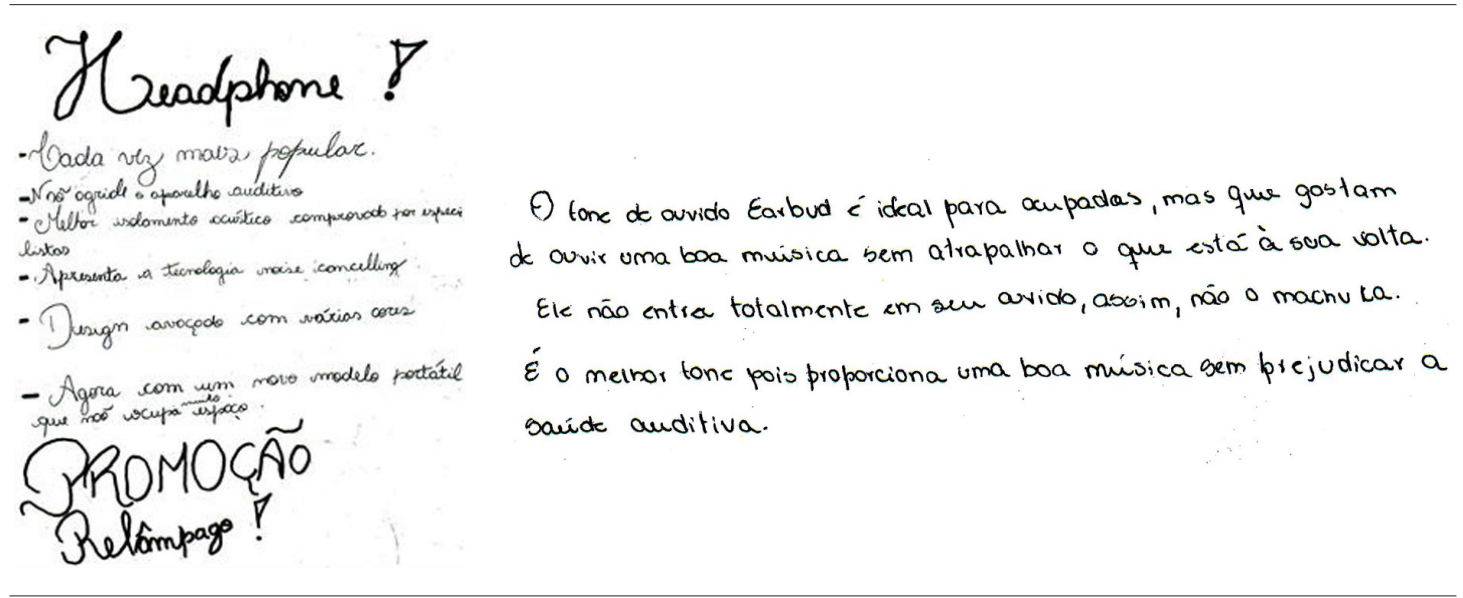

Fonte: elaborado pelos autores.

Ao analisar as duas propagandas (Figura 1), é possível perceber, claramente, que os estudantes utilizaram argumentos persuasivos para divulgar o produto (no caso, fones) e convencer seus consumidores em potencial. Isso é uma evidência de que a argumentação é atividade de natureza discursiva, conforme defendem Eemeren, Grootendorst e Kruiger (1987) e Leitão e Almeida (2000).

Dessa forma, as propagandas refletiram a leitura crítica (FRANCISCO JUNIOR, 2011) de cada grupo de alunos, tendo sido decidido, na negociação entre os colegas, o que deveria constar na propaganda, de modo a vender o produto levando em consideração algumas das características individuais de cada fone abordadas no TDC.

Logo, a discussão de cada um dos quatro TDC em sala de aula propiciou não só a abordagem da conceituação Física necessária ao entendimento de cada um dos temas, mas foi além, pois favoreceu a vinculação entre o conteúdo científico ensinado e seus aspectos sociais, políticos e tecnológicos. Ademais, contribuiu para despertar interpretações múltiplas dos TDC. Nessa perspectiva, Nascimento e Souza (2003) ressaltam que os TDC são materiais que proporcionam leituras diferenciadas, pois propiciam a discussão de temas atuais com foco não apenas no conteúdo científico.

Com relação ao desenvolvimento das habilidades de leitura, de escrita e de argumentação, é importante destacar que é um processo lento, evidenciado ao longo da sequência implementada de AD com TDC. Portanto, as inserções de atividades de leitura devem ocorrer com regularidade. Para isso, o professor deve ter o cuidado de trazer textos para as aulas que estejam de acordo com o conteúdo a ser trabalhado e com seus objetivos preestabelecidos, mas que também sejam de interesse de seus alunos.

Outro aspecto que corrobora com a necessidade de se desenvolver atividades de leituras com certa frequência, principalmente nas aulas de Física, é que, em um primeiro momento, elas podem causar certa estranheza nos alunos, fato que foi comprovado com esses alunos, prova- 
velmente, devido à falta de contato que eles tinham com esse tipo de recurso didático. Assim, nas primeiras AD com TDC, os alunos demonstravam insegurança para o desenvolvimento das tarefas, buscavam as respostas com a professora (em formação) em vez de debaterem com os colegas e não se permitiam opinar sobre os textos lidos. Com o passar do tempo, em especial, nessa última $\mathrm{AD}$, observou-se que os alunos foram adquirindo autonomia, passaram a se posicionar criticamente sobre os textos lidos e, durante a realização das tarefas e discussões em sala de aula, defenderam seus argumentos com base em conexões entre as leituras já realizadas e/ou nos conteúdos físicos estudados. Sendo assim, por meio das estratégias de leitura utilizadas, o cenário de passividade e dependência dos alunos em relação à professora foi mudando aos poucos. Assim, as discussões foram se tornando cada vez mais proveitosas e envolventes, permitindo que muitas questões interessantes fossem abordadas.

Reitera-se que, a partir do terceiro texto, os alunos deixaram de ter uma postura de leitura passiva (busca de informações) frente ao TDC e às respectivas discussões, e passaram a fazer a leitura do texto - pretexto. Como consequência, os alunos conseguiram expor e defender suas opiniões acerca do texto lido com base em conhecimento científico. Leitão e Almeida (2000) ressaltam que a argumentação é uma atividade que envolve oposição entre as opiniões dos envolvidos. Assim, entende-se que, no contexto da sala de aula, a argumentação é uma forma de interação comunicativa em que docentes e alunos confrontam seus saberes e opiniões sobre um tema com o propósito de convencer um ao outro, utilizando preferencialmente critérios científicos. Nesse sentido, o papel do professor é de fundamental importância para guiar as discussões no ensino da conceituação científica.

\section{Considerações finais}

Os resultados obtidos por meio da sequência de atividades didáticas sinalizam indícios de avanços dos alunos em relação à leitura, à escrita e à capacidade de argumentação. Assim, foi possível constatar que a forma como se deu a organização e o desenvolvimento de cada atividade de pré/durante/pós-leitura, bem como os temas propostos para abordar os conteúdos científicos, foram fatores decisivos para se realizar a articulação entre os conteúdos físicos e os temas de cada TDC trabalhado, promovendo o desenvolvimento das habilidades relacionadas às expressões oral e escrita.

Além disso, percebeu-se que as diferentes formas de trabalho propostas para os distintos TDC motivaram os alunos a participarem das atividades de leitura nas aulas. Durante as discussões dos TDC, percebeu-se ainda que os alunos se interessaram pelos temas abordados nos textos, apresentaram dúvidas, questionamentos, novas informações que muitas vezes iam além delas no texto, embora estivessem relacionadas ao tema do texto. Isso demonstra o poder argumentativo dos alunos em relação às informações veiculadas nos textos estudados, no seu cotidiano ou até mesmo nos meios de comunicação.

Infere-se que a proposta de uso recorrente e sistemático de atividades que envolvam TDC em aulas de Física, detalhada neste artigo, mostrou ser um caminho possível para estabelecer relações entre o conteúdo científico e temas relacionados ao cotidiano, assim como para o desenvolvimento das habilidades de leitura, escrita e capacidade de argumentação.

Destaca-se que as estratégias empregadas para as etapas de pré/durante/pós-leitura em cada atividade didática poderiam ser utilizadas para trabalhar qualquer outro tipo de texto 
(incluindo os do livro didático). O importante é que cada atividade envolvendo texto contemple essas três etapas de leitura, pois, por um lado, as tarefas propostas em cada etapa motivam o aluno a ler e a discutir o texto; por outro, os resultados das tarefas trazem subsídios para o professor avaliar as aprendizagens dos alunos durante o processo de leitura.

O destaque deste trabalho é o caráter inovador da atividade com TDC, que procurou articular o uso de TDC e a abordagem de conteúdos físicos mediante o uso de estratégias de leitura. Essa nova forma de trabalhar a leitura de TDC nas aulas de Física se diferencia dos trabalhos reportados na literatura, conforme indica o levantamento bibliográfico discutido neste estudo.

\section{Agradecimentos}

Os autores agradecem a cooperação da Coordenação de Aperfeiçoamento de Pessoal de Nível Superior (Capes).

\section{Referências}

ABREU, L. N.; MASSI, L.; QUEIROZ, S. L. Textos de divulgação científica no ensino superior de química. In: ENCONTRO NACIONAL DE PESQUISA EM EDUCAÇÃO EM CIÊNCIAS, 6., 2007, Florianópolis. Anais... Florianópolis, 2007.

ALMEIDA, M. J. P. M.; MOZENA, E. R. Luz e outras formas de radiação eletromagnéticas, leitura na $8^{a}$ série do ensino fundamental. Revista Brasileira de Ensino de Física, São Paulo, v. 22, n. 3, p. 426-433, 2000.

ALMEIDA, M. J. P. M.; RICON, A. E. Divulgação científica e texto literário: uma perspectiva cultural em aulas de física. Caderno Catarinense Ensino de Física, Florianópolis, v. 10, n. 1, p. 7-13, 1993.

ALMEIDA, M. J. P. M.; SILVA, H. C.; BABICHAK, C. C. O movimento, a mecânica e a física no ensino médio. Revista Brasileira de Ensino de Física, São Paulo, v. 21, n. 1, p.195-201, 1999.

ALMEIDA, M. J. P. M. ; SILVA, H. C. ; MACHADO, J. L. M. Condições de produção no funcionamento da leitura na educação em física. Revista Brasileira de Pesquisa em Educação em Ciências, Porto Alegre, v. 1, n. 1, p. 5-17, 2001.

ASSIS, A.; TEIXEIRA, O. P. Dinâmica discursiva e o ensino de física: análise de um episódio de ensino envolvendo o uso de um texto alternativo. Ensaio: pesquisa em educação em ciências, Belo Horizonte, v. 9, n. 2, p. 1-17, 2007.

ASSIS, A. et al. Aprendizagem significativa do conceito de ressonância. Revista Brasileira de Pesquisa em Educação em Ciências, São Paulo, v. 12, n. 1, 2012.

BARDIN, L. Análise de conteúdo. Lisboa: Edições 70, 2004. 
BORGES, A. T.; RODRIGUES, B. A. O ensino da física do som baseado em investigações. Ensaio: pesquisa em educação em ciências, Belo Horizonte, v. 7, n. 2, p. 1-24, 2005.

CHARAUDEAU, P.; MAINGUENEAU, D. Dicionário de análise do discurso. 2. ed. São Paulo: Contexto, 2006.

DIAS, P. M. C.; SANTOS, W. M. S.; SOUZA, M. T. M. A gravitação universal: um texto para o ensino médio. Revista Brasileira de Ensino de Física, São Paulo, v. 26, n. 3, p. 257-271, 2004.

DUNN, R. Tudo o que você sabe sobre calorias está errado. Scientific American Brasil, São Paulo, v. 12, n. 137, 2013. Número especial.

EEMEREN, V. F. H.; GROOTENDORST, R.; KRUIGER, T. Handbook of argumentation theory: a critical survey of classical backgrounds and modern studies. Berlin: Walter de Gruyter, 1987.

FERREIRA, L. N. A.; QUEIROZ, S. L. Textos de divulgações científicas no ensino de ciências: uma revisão. Alexandria: revista de educação em ciência e tecnologia, Florianópolis, v. 5, n. 1, p. 3-31, 2012.

FRANCISCO JUNIOR, W. E. Analisando uma estratégia de leitura baseada na elaboração de perguntas com respostas. Investigações em Ensino de Ciências, Porto Alegre, v. 16, n.1, p.161-175, 2011.

GERALDI, J. W. Prática da leitura de textos na escola. Leitura: teoria \& prática, Campinas, v. 3, p. 25-32, 1984.

KLEIMAN, A. Oficina de leitura: teoria e prática. Campinas: Pontes, 2007.

LEITÃO, S.; ALMEIDA, E. G. S. A produção de contra-argumentos na escrita infantil.

Psicologia: reflexão e crítica, Porto Alegre, v. 13, n. 3, p. 351-361, 2000.

MAFFIA, A. M. C. et al. Livro didático de ciências: o real e o idealizado em sua seleção. In: ENCONTRO PERSPECTIVAS DO ENSINO DE BIOLOGIA, 8., 2002, São Paulo. Anais... São Paulo, 2002.

MANFRIN, J.; MACEDO, D. Para ouvir melhor. Veja, São Paulo, v. 96, fev. 2014.

MARTINS, I.; CASSAB, M.; ROCHA, M. B. Análise do processo de re-elaboração discursiva de um texto de divulgação científica para um texto didático. In: ENCONTRO NACIONAL DE PESQUISA EM EDUCAÇÃO EM CIÊNCIAS, 3., 2001, Atibaia. Anais... São Paulo: ABRAPEC, 2001.

MARUM, D. Potência? Torque? Consumo? Saiba o que considerar ao comprar carro.

Oficina do G1, 28 abr. 2014. Disponível em: <http://g1.globo.com/carros/oficina-do-g1/ noticia/2014/04/potencia-torque-consumo-saiba-o-que-considerar-ao-comprar-carro.html>. Acesso em: 29 jul. 2015.

MOSS, B.; LOH, V.S. 35 Estratégias para desenvolver a leitura com textos

informativos. Porto Alegre: Penso, 2012. 
MOTTA, F. Gasolina ou etanol: qual vale mais a pena? O Estado de São Paulo, São Paulo, 14 dez. 2013. Jornal do Carro. Disponível em: <http://jornaldocarro.estadao.com.br/carros/ gasolina-ou-etanol-qual-vale-mais-a-pena/>. Acesso em: 25 out. 2017.

NASCIMENTO, T. G.; SOUZA, S. C. Modos de leitura de textos de divulgação científica. In: ENCONTRO NACIONAL DE PESQUISA EM EDUCAÇÃO EM CIÊNCIAS, 3., 2003, Bauru. Anais... São Paulo: ABRAPEC, 2003.

RIBEIRO, R. A.; KAWAMURA, M. R. D. A ciência em diferentes vozes: uma análise de textos de divulgação científica. In: ENCONTRO NACIONAL DE PESQUISA EM ENSINO DE CIÊNNCIAS, 5., 2005, Bauru. Anais... Bauru, 2005.

ROCHA, M. R. Contribuições dos textos de divulgação científicas para o ensino de ciências na perspectiva dos professores. Acta Scientiae, Canoas, v. 14, n. 1, p. 132-150, 2012.

RÖSING, T. M. K. A formação do professor e a questão da leitura. Passo Fundo: UPF Editora, 2003.

SÁ, L. P.; QUEIROZ, S. L. Promovendo a argumentação no ensino superior de Química. Química Nova, São Paulo, v. 30, n. 8, p. 2035-2042, 2007.

SALÉM, S.; KAWAMURA, M. R. O texto de divulgação e o texto didático: conhecimentos diferentes? In: ENCONTRO DE PESQUISADORES EM ENSINO DE FÍSICA, 5., 1996, Belo Horizonte. Anais... Belo Horizonte: SBF, 1996. 1 CD-ROM.

SETLIK, J.; HIGA, I. Leitura e produção escrita no ensino médio como meio de produção de conhecimento. Experiências em Ensino de Ciências, Cuiabá, v. 9, n. 1, p. 83-95, 2014.

SILVA, A. C.; ALMEIDA, M. J. P. M. A leitura por alunos do ensino médio de um texto considerado de alto grau de dificuldade. Alexandria: revista de educação em ciência e tecnologia, Florianópolis, v. 7, n. 1, p. 49-73, 2014.

A noção de mobilização na associação da física a objetos tecnológicos

contemporâneos. Ciência \& Educação, Bauru, v. 21, n. 2, p. 417-434, 2015.

SILVA, E. T. Ciência, leitura e escola. In: ALMEIDA, M. J. P. M.; SILVA, H. C. (Org.).

Linguagens, leituras e ensino de ciências. Campinas: Mercado das Letras, 1998. p. 121-130.

SILVA, J. A.; KAWAMURA, M. R. D. A natureza da luz: uma atividade com texto de divulgação científica em sala de aula. Caderno Brasileiro de Ensino de Física, Florianópolis, v. 18, n. 3, p. 316-339, 2001.

SOLÉ, I. Estratégia de leitura. Porto Alegre: Artmed, 1998.

SOUZA, S. C. Leitura e fotossíntese: proposta de ensino numa abordagem cultural. 2000. 313 f. Tese (Doutorado em Educação) - Faculdade de Educação, Universidade Estadual de Capinas, Campinas, 2000. 
Correia, D.; Decian, E.; Sauerwein, I. P. S.

TERRAZZAN, E. A.; GABANA, M. Um estudo sobre o uso de atividades didáticas com texto de divulgação científica em aulas de física. In: ENCONTRO NACIONAL DE PESQUISA EM EDUCAÇÃO EM CIÊNCIAS, 4., 2003, Bauru. Anais... São Paulo: ABRAPEC, 2003.

ZAMBONI, L. M. S. Cientistas, jornalistas e a divulgação científica: subjetividade e heterogeneidade no discurso da divulgação científica. São Paulo: Autores Associados, 2001.

ZANOTELLO, M.; ALMEIDA, M. J. P. M. Leitura de um texto de divulgação científica em uma disciplina de física básica na educação superior. Ensaio: pesquisa em educação em ciências, Belo Horizonte, v. 15, n. 3, p. 113-130, 2013.

Artigo recebido em 28/04/2016. Aceito em 26/03/2017.

Endereço para contato: UFSM, Programa de Pós-graduação

Educação em Ciências, Av. Roraima, 1000, Cidade Universitária, Camobi, CEP 97105-900, Santa Maria, RS, Brasil. 